\title{
Prognostic significance of PD-L1 expression and CD8+ T cell infiltration in pulmonary neuroendocrine tumors
}

Haiyue Wang ${ }^{1 \dagger}$, Zhongwu Li ${ }^{1 \dagger}$, Bin Dong ${ }^{2}$, Wei Sun ${ }^{1}$, Xin Yang ${ }^{1}$, Ruping Liư ${ }^{3}$, Lixin Zhou' ${ }^{1}$ Xiaozheng Huang ${ }^{1}$, Ling Jia ${ }^{1}$ and Dongmei Lin ${ }^{1 *}$

\begin{abstract}
Background: Recent research supports a significant role of immune checkpoint inhibitors in the treatment of solid tumors. However, relevant reports for programmed death-ligand 1 (PD-L1) and CD8+ tumor-infiltrating lymphocytes (TILS) in pulmonary neuroendocrine tumors (PNETs) have not been fully studied. Therefore, we investigated PNETs for the expression of PD-L1 and infiltration by CD8+ TILs as well as the prognostic value of both factors.

Methods: In total, 159 specimens of PNETs (35 TC, 2 AC, 28 LCNEC, 94 SCLC) were included in this study. Immunohistochemistry (IHC) was used to detect the expression of PD-L1 in these cases. Cases demonstrating $\geq 5 \%$ tumor cell expression or any expression (> 1\%) of PD-L1 on immune cells were considered positive. CD8

+ TILs both within stroma and tumor areas of invasive carcinoma were analyzed using whole-slide digital imaging. Manual regional annotation and machine cell counts were performed for each case.

Results: Positive expression of PD-L1 was observed in 72 cases (45.3\%), including 9 cases (5.7\%) with expression exclusively on tumor cells, 46 cases (28.9\%) with expression exclusively on immune cells, and 17 cases (10.7\%) with the expression on tumor cells and immune cells. PD-L1 expression was associated with necrosis $(p<0.001)$, high pathologic grade $(p<0.001)$ and histologic type $(p<0.001)$. No correlation was observed with overall survival (OS) $(p=0.158)$ or progression-free survival (PFS) $(p=0.315)$. In contrast, higher CD8+ T cell density was associated with the absence of vascular invasion $(p=0.004)$, histologic type $(p=0.005)$, negative lymph node metastasis $(p=0.005)$ and lower clinical staging $(p=0.007)$. Moreover, multivariate analysis revealed that CD8+ stromal TIL was an independent prognostic factor for improved OS ( $p=0.009)$ and PFS ( $p=0.002)$.

Conclusion: PD-L1 was expressed in approximately half of the PNETs. The majority of the expression was observed in immune cells. Positive expression of PD-L1 showed no correlation with OS or PFS, while higher CD8+ TILs within stroma was proved to be an independent prognostic factor for favorable OS and PFS of PNETS.
\end{abstract}

Keywords: Pulmonary neuroendocrine tumor, PD-L1, CD8+ TILs

\footnotetext{
* Correspondence: lindm100142@163.com

${ }^{\dagger}$ Haiyue Wang and Zhongwu Li contributed equally to this work. ${ }^{1}$ Key Laboratory of Carcinogenesis and Translational Research (Ministry of Education), Department of Pathology, Peking University Cancer Hospital \& Institute, No. 52 Fucheng Road, Haidian District, Beijing 100142, People's Republic of China

Full list of author information is available at the end of the article
}

(c) The Author(s). 2018 Open Access This article is distributed under the terms of the Creative Commons Attribution 4.0 International License (http://creativecommons.org/licenses/by/4.0/), which permits unrestricted use, distribution, and reproduction in any medium, provided you give appropriate credit to the original author(s) and the source, provide a link to the Creative Commons license, and indicate if changes were made. The Creative Commons Public Domain Dedication waiver (http://creativecommons.org/publicdomain/zero/1.0/) applies to the data made available in this article, unless otherwise stated. 


\section{Background}

Neuroendocrine lung tumors represent a spectrum of low-grade typical carcinoids (TC), atypical carcinoids (AC), high-grade large cell neuroendocrine carcinoma (LCNEC) and small cell lung carcinoma (SCLC). SCLC is the most aggressive and most common of all malignant neuroendocrine tumors, with an incidence of 15-20\%. LCNEC represents approximately $3 \%$ of lung tumors. TC accounts for $1-2 \%$, while $\mathrm{AC}$ is the rarest of the lung neuroendocrine tumors $(0.1-0.2 \%)$ [1-3]. Traditional treatments for high-grade malignancy, which include chemotherapy and radiation, have remained unchanged for decades. Prognosis remains dismal for these patients [4]. Therefore, to improve the prognosis of PNETs, a promising therapeutic strategy is urgently needed.

In the process of tumorigenesis, neoplastic transformation alters the structure of the normal tissue, leading to the activation of effector T cells, which then seeks to eliminate the transformed cells. Novel immunotherapy targeting immune checkpoint molecules such as programmed death-ligand 1 (PD-L1), based on the mechanism of cancer-immune escape, have successfully garnered increasing attention. Programmed death ligand 1 (PD-L1; also called B7-H1 or CD274) can be detected in many cancer cells and immune cells including the antigen-presenting cells (APCs) [5]. During the development of human cancer, the PD-L1 molecule is abnormally activated and overexpressed, which may suppress $\mathrm{T}$ cell migration, proliferation, secretion of cytotoxic mediators, and restrict cancer cell killing [6]. Therefore, monoclonal antibodies (mAbs) blocking the PD-L1 pathway or immunomodulatory agents with similar effects may improve anticancer immunity via enhancing $\mathrm{T}$ cell functions. Monoclonal antibodies targeting PD-L1 or PD-1 are currently being investigated in clinical trials. The results obtained to date have demonstrated remarkable clinical responses in many different types of cancer [6-10].

Cytotoxic lymphocytes (CTLs), which play a critical role in the anticancer response, are actively suppressed in the tumor microenvironment [11]. Some CTLs manage to be released into circulation, then migrate into tumor tissue through complicated interactions with adhesion receptors, at which point they are called tumor-infiltrating lymphocytes (TILs) [12]. Given that PD-L1 on tumor cells or immune cells interacts with CD8 expressed on $\mathrm{T}$ cells in the tumor environment, a comprehensive analysis of CD8/PD-L1 related molecules might provide important information for determining the clinical relevance to the neuroendocrine tumors of the lung. However, to the best of our knowledge, expression of PD-L1 on PNETs has not been fully studied [13].

In this study, we investigated the pattern of PD-L1 expression and the density of CD8+ TILs in PNETs. Moreover, we analyzed the clinicopathological characteristics with the expression of PD-L1 and the number of CD8+ TIL levels. We also performed a survival analysis to determine the correlation of PD-L1 expression and CD8+ TIL counts with OS and PFS.

\section{Methods \\ Patient cohort}

A total of 159 patients with PNETs who underwent pulmonary lobectomy or lymph node resection at Peking University Cancer Hospital (Beijing, China) from 2010 to 2015 were included in this study. Of those cases, 35 were TC, 2 were AC, 28 were LCNEC, and 94 were SCLC. All cases were reviewed by two experienced pathologists (Zhongwu $\mathrm{Li}$ and Bin Dong) to confirm the diagnosis based on the current WHO criteria for neuroendocrine lung tumors. The staging was undertaken according to the 8th edition AJCC tumor, lymph node, metastasis (TNM) classification. All the clinical characteristics (including age, gender, histologic type, necrosis, vascular invasion, preoperative chemotherapy, lymph node metastasis, and clinical TNM staging) were collected.

\section{Immunohistochemistry}

Serial sections with a thickness of $4 \mu \mathrm{m}$ from the whole formalin-fixed paraffin-embedded (FFPE) samples of PNETs were cut onto glass slides, followed by IHC staining. Evaluation of PD-L1 was performed using a rabbit anti-PD-L1 monoclonal antibody (clone SP142; ZSGB-BIO, Beijing, China) at a working solution and incubated for $15 \mathrm{~min}$ at $37{ }^{\circ} \mathrm{C}$ on an autostainer (BOND-MAX, LEICA, Leica Biosystems Newcastle Ltd., Newcastle, UK). Cases demonstrating $\geq 5 \%$ tumor cell expression (membrane) or any expression (>1\%) of PD-L1 on immune cells (membrane or cytoplasm) were considered positive [14]. Slides stained with CD8 were labeled by a rabbit anti-CD8 monoclonal antibody (clone SP16; ZSGB-BIO, Beijing, China) at a working solution and incubated for $36 \mathrm{~min}$ at $37{ }^{\circ} \mathrm{C}$ on an autostainer (BenchMark ULTRA, Roche, Ventana Medical Systems, Oro Valley, AZ, USA). For each case, manual regional annotation and machine cell counts were used to measure cell density in intratumoral as well as stromal areas of invasive carcinoma. CD8+ TIL density was analyzed by whole slide digital scanning using an Digital Pathology Scanner (Aperio VERSA, Leica Biosystems, Buffalo Grove, IL, USA), and the scoring was assessed on an Aperio Scanscope (Aperio Technologies; USA) by the method of rare event tissue test. Positive cell counts were measured in 4 peritumoral and 6 intratumoral non-overlapping fields using fixed areas of 1.44 square millimeters. The grading system was defined as two groups according to the median $\mathrm{CD} 8+\mathrm{T}$ cell density in stroma and intratumor. 


\section{Statistical analysis}

SPSS 17.0 version (IBM Corporation, Armonk, NY, USA) was used for all statistical analyses. Correlations between CD8+ T cell density and PD-L1 expression with the clinicopathological variables were performed using the Pearson's chi-square and Fisher's exact test. Survival analysis was performed using the univariate Kaplan-Meier method. Multivariate analysis was performed with the Cox proportional hazards model. Overall survival was calculated from the date of pathological diagnosis to time of death or last follow-up. Progression-free survival was calculated from date of pathological diagnosis to time of last clinical evidence of recurrence, progression, or death. Two-sided $p$ value $<0.05$ was considered statistically significant.

\section{Results}

Patient clinicopathological characteristics and PD-L1 immunoreactivity

The clinicopathological features of 159 patients diagnosed as neuroendocrine tumors of lung are

Table 1 Clinical characteristics in the four subtypes

\begin{tabular}{|c|c|c|c|c|c|c|}
\hline \multirow[t]{2}{*}{ Variable } & All tumors & $\mathrm{TC}$ & $A C$ & LCNEC & $\mathrm{SCLC}$ & \multirow[t]{2}{*}{ NA } \\
\hline & $159(100.0)$ & $35(100.0)$ & $2(100.0)$ & $28(100.0)$ & $94(100.0)$ & \\
\hline \multicolumn{7}{|l|}{ Age } \\
\hline$<=59.5$ & $78(49.1)$ & $25(71.4)$ & $2(100.0)$ & $12(42.9)$ & $39(41.5)$ & \\
\hline$>59.5$ & $81(50.9)$ & $10(28.6)$ & $0(0.0)$ & $16(57.1)$ & $55(58.5)$ & \\
\hline \multicolumn{7}{|l|}{ Gender } \\
\hline Male & $109(68.6)$ & $17(48.6)$ & $0(0.0)$ & $23(82.1)$ & $69(73.4)$ & \\
\hline Female & $50(31.4)$ & $18(51.4)$ & $2(100.0)$ & $5(17.9)$ & $25(27.6)$ & \\
\hline \multicolumn{7}{|l|}{ Necrosis } \\
\hline No & $85(53.5)$ & $35(100.0)$ & $0(0.0)$ & $9(32.1)$ & $41(43.6)$ & \\
\hline Yes & $74(46.5)$ & $0(0.0)$ & $2(100.0)$ & $19(67.9)$ & $53(56.4)$ & \\
\hline \multicolumn{7}{|l|}{ Vascular invasion } \\
\hline No & $129(81.1)$ & $34(97.1)$ & $1(50.0)$ & $22(78.6)$ & $72(76.6)$ & \\
\hline Yes & $30(18.9)$ & $1(2.9)$ & $1(50.0)$ & $6(21.4)$ & $22(23.4)$ & \\
\hline \multicolumn{7}{|l|}{ Preoperative therapy } \\
\hline No & $150(94.3)$ & $35(100.0)$ & $2(100.0)$ & $27(96.4)$ & $86(91.5)$ & \\
\hline Yes & $9(5.7)$ & $0(0.0)$ & $0(0.0)$ & $1(3.6)$ & $8(8.5)$ & \\
\hline \multicolumn{7}{|l|}{ First location } \\
\hline Lung & $131(82.4)$ & $35(100.0)$ & $2(100.0)$ & $28(100.0)$ & $66(70.2)$ & \\
\hline Lymph Node & $28(17.6)$ & $0(0.0)$ & $0(0.0)$ & $0(0.0)$ & $28(29.8)$ & \\
\hline Lymph Node Metastasis & & & & & & $13(8.2)$ \\
\hline No & $83(52.2)$ & $32(97.0)$ & $1(50.0)$ & $14(60.9)$ & $36(40.9)$ & \\
\hline Yes & $63(47.8)$ & $1(3.0)$ & $1(50.0)$ & $9(39.1)$ & $52(59.1)$ & \\
\hline Clinical Staging & & & & & & $15(9.4)$ \\
\hline I & $70(48.6)$ & $30(90.9)$ & $1(50.0)$ & $10(43.5)$ & $29(33.7)$ & \\
\hline$\|$ & $27(18.8)$ & $2(6.1)$ & $0(0.0)$ & $9(39.1)$ & $16(18.6)$ & \\
\hline III & $47(32.6)$ & $1(3.0)$ & $1(50.0)$ & $4(17.4)$ & $41(47.7)$ & \\
\hline \multicolumn{7}{|l|}{ Patterns of PD-L1 } \\
\hline Tumor ${ }^{\text {pos }}$ stroma $a^{\text {neg }}$ & $9(5.7)$ & $3(8.6)$ & $0(0.0)$ & $5(17.8)$ & $1(1.1)$ & \\
\hline Stroma ${ }^{\text {pos }}$ tumor $^{\text {neg }}$ & $46(28.9)$ & $0(0.0)$ & $0(0.0)$ & $12(42.9)$ & $34(36.2)$ & \\
\hline Tumor and stroma $a^{\text {pos }}$ & $17(10.7)$ & $0(0.0)$ & $0(0.0)$ & $4(14.3)$ & $13(13.8)$ & \\
\hline Tumor and stromaneg & $87(54.7)$ & $32(91.4)$ & $2(100.0)$ & $7(25.0)$ & $46(48.9)$ & \\
\hline \multicolumn{7}{|c|}{ CD8 density $/ \mathrm{mm}^{2}$ in stroma } \\
\hline$\leq 264.6 / \mathrm{mm}^{2}$ & $80(50.3)$ & $23(65.7)$ & $0(0.0)$ & $7(25.0)$ & $50(53.2)$ & \\
\hline$>264.6 / \mathrm{mm}^{2}$ & $79(49.7)$ & $12(34.3)$ & $2(100.0)$ & $21(75.0)$ & $44(46.8)$ & \\
\hline
\end{tabular}

Abbreviation: NA not available 
presented in Table 1. The study included 109 males (68.6\%) and 50 females (31.4\%). Median age was 59.5 years (range, 30 to 83 ). A small minority of patients $(5.7 \%)$ had received neoadjuvant chemotherapy before surgery, while 148 cases did not. For most cases, the primary site was in the lung $(n=$ $131,82.4 \%)$. Of the 159 samples, most tumors showed no vascular invasion $(n=129,81.1 \%)$. Approximately half of the cases had tumor necrosis $(n$ $=74,46.5 \%)$. Lymph node metastasis was detected in 63 patients $(47.8 \%)$. Tumors were classified as stage I $(n=70,48.6 \%)$, stage II $(n=27,18.8 \%)$, or stage III $(n=47,32.6 \%)$.

PD-L1 was positively expressed in 72 cases $(45.3 \%)$, including 9 with expression exclusively on tumor cells (5.7\%), 46 with expression exclusively on immune stromal cells (28.9\%), and 17 with expression both on tumor cells and immune cells (10.7\%). Membranous and cytoplasmic expression of PD-L1 protein was detected in four types of PNETs, including SCLC $(n=$ 48, 66.7\%), LCNEC $(n=21,29.2 \%)$, AC $(n=0,0.0 \%)$, and TC $(n=3,4.1 \%)$.

Table 2 The association between PD-L1 expression, CD8+ T cell infiltration and clinicopathologic parameters in PNETs

\begin{tabular}{|c|c|c|c|c|c|c|c|c|}
\hline \multirow[t]{2}{*}{ Variable } & \multirow[b]{2}{*}{$\mathrm{N}(\%)$} & \multicolumn{3}{|c|}{ PD-L1 expression } & \multicolumn{3}{|c|}{ CD8+ $T$ cell density in stroma } & \multirow[t]{2}{*}{ NA } \\
\hline & & Positive & Negative & $p$ & $\leq 264.6 / \mathrm{mm}^{2}$ & $>264.6 / \mathrm{mm}^{2}$ & $p$ & \\
\hline Total & $159(100.0)$ & $72(45.3)$ & $87(54.7)$ & & $80(50.3)$ & $79(49.7)$ & & \\
\hline Age & & & & 0.241 & & & 0.578 & \\
\hline$\leq 59.5$ & $78(49.1)$ & $39(54.2)$ & $39(44.8)$ & & $41(51.3)$ & $37(46.8)$ & & \\
\hline$>59.5$ & $81(50.9)$ & $33(45.8)$ & $48(55.2)$ & & $39(48.7)$ & $42(53.2)$ & & \\
\hline Gender & & & & 0.365 & & & 0.189 & \\
\hline Male & 109 (68.6) & $52(72.2)$ & $57(65.5)$ & & $51(63.8)$ & $58(73.4)$ & & \\
\hline Female & $50(31.4)$ & $20(27.8)$ & $30(34.5)$ & & $29(36.3)$ & $21(26.6)$ & & \\
\hline Necrosis & & & & $<0.001^{*}$ & & & 0.096 & \\
\hline No & $85(53.5)$ & $17(23.6)$ & $68(78.2)$ & & $48(60.0)$ & $37(46.8)$ & & \\
\hline Yes & $74(46.5)$ & $55(76.4)$ & $19(21.8)$ & & $32(40.0)$ & $42(53.2)$ & & \\
\hline Vascular invasion & & & & 0.072 & & & $0.004^{*}$ & \\
\hline No & $129(81.1)$ & $54(75.0)$ & $75(86.2)$ & & $72(90.0)$ & $57(72.2)$ & & \\
\hline Yes & $30(18.9)$ & $18(25.0)$ & $12(13.8)$ & & $8(10.0)$ & $22(27.8)$ & & \\
\hline Preoperative therapy & & & & 0.538 & & & 0.113 & \\
\hline No & $148(93.1)$ & $68(94.4)$ & $80(92.0)$ & & $77(96.3)$ & $71(89.8)$ & & \\
\hline Yes & $11(6.9)$ & $4(5.6)$ & $7(8.0)$ & & $3(3.7)$ & $8(10.2)$ & & \\
\hline Tumor type & & & & $<0.001^{*}$ & & & $0.005^{*}$ & \\
\hline SCLC & $94(59.1)$ & $48(51.1)$ & $46(48.9)$ & & $50(53.2)$ & $44(46.8)$ & & \\
\hline LCNEC & $28(17.6)$ & $21(75.0)$ & $7(25.0)$ & & $7(25.0)$ & $21(75.0)$ & & \\
\hline TC & $35(22.0)$ & $3(8.6)$ & $32(91.4)$ & & $23(65.7)$ & $12(34.3)$ & & \\
\hline$A C$ & $2(1.3)$ & $0(0.0)$ & $2(100.0)$ & & $0(0.0)$ & $2(100.0)$ & & \\
\hline Pathological grading & & & & $<0.001^{*}$ & & & 0.100 & \\
\hline High & $122(76.7)$ & $69(95.8)$ & $53(60.9)$ & & $57(71.2)$ & $65(82.3)$ & & \\
\hline Low & $37(23.3)$ & $3(4.2)$ & $34(39.1)$ & & $23(28.8)$ & $14(17.7)$ & & \\
\hline Lymph node metastasis & & & & 0.170 & & & $0.005^{*}$ & $13(8.2)$ \\
\hline No & $83(56.8)$ & $34(50.7)$ & $49(62.8)$ & & $33(45.2)$ & $50(68.5)$ & & \\
\hline Yes & $63(43.2)$ & $33(49.3)$ & $30(37.2)$ & & $40(54.8)$ & $23(31.5)$ & & \\
\hline Clinical Staging & & & & 0.314 & & & $0.007^{*}$ & $15(9.4)$ \\
\hline । & 70 (48.6) & $29(41.4)$ & 41 (58.6) & & 27 (38.6) & $43(61.4)$ & & \\
\hline$\|$ & $27(18.8)$ & $10(37.0)$ & $17(63.0)$ & & $14(51.9)$ & $13(48.1)$ & & \\
\hline III & 47 (32.6) & $25(53.2)$ & $22(46.8)$ & & 32 68.1) & 15 (31.9) & & \\
\hline
\end{tabular}




\section{Association between PD-L1 expression and clinicopathologic parameters}

Associations between PD-L1 and clinical parameters in patients with PNETs are described in Table 2. The expression of PD-L1 was significantly associated with the presence of tumor necrosis $(p<0.001)$, high pathologic grade $(p<0.001)$, and histologic type (particularly for LCNEC) $(p<0.001)$. There was no significant association between
PD-L1 and age $(p=0.241)$, gender $(p=0.365)$, prior neoadjuvant therapy $(p=0.538)$, vascular invasion $(p=0.072)$, lymph node metastasis $(p=0.170)$, or clinical staging $(p=$ 0.314). The pattern of PD-L1 expression was reclassified as tumor-positive and stroma-positive. Statistical correlations between tumor cell or immune cell and clinical parameters are present in Table 3. The PD-L1 positive expression in immune cells was associated with tumor

Table 3 The expression patterns of PD-L1 to clinicopathologic parameters in PNETs

\begin{tabular}{|c|c|c|c|c|c|c|c|c|}
\hline & & PD-L1 exp & & & & & & NA \\
\hline & $N(\%)$ & Tumor pos & Tumor $^{\text {neg }}$ & $p$ & Stroma ${ }^{\text {pos }}$ & Stromaneg & $p$ & \\
\hline Total & $159(100.0)$ & $26(16.4)$ & $133(83.6)$ & & $63(39.6)$ & $96(60.4)$ & & \\
\hline Age & & & & 0.593 & & & 0.497 & \\
\hline$\leq 59.5$ & $78(49.1)$ & $14(53.8)$ & $64(48.1)$ & & $33(52.4)$ & $45(46.9)$ & & \\
\hline$>59.5$ & $81(50.9)$ & $12(46.2)$ & $69(51.9)$ & & $30(47.6)$ & $51(53.1)$ & & \\
\hline Gender & & & & 0.142 & & & 0.527 & \\
\hline Male & 109 (68.6) & $21(80.8)$ & $88(66.2)$ & & $45(71.4)$ & $64(66.7)$ & & \\
\hline Female & $50(31.4)$ & $5(19.2)$ & $45(33.8)$ & & 18 (28.6) & $32(33.3)$ & & \\
\hline Necrosis & & & & 0.094 & & & $<0.001^{*}$ & \\
\hline No & $85(53.5)$ & $10(38.5)$ & $75(56.4)$ & & $11(17.5)$ & $74(77.1)$ & & \\
\hline Yes & $74(46.5)$ & $16(61.5)$ & $58(43.6)$ & & $52(82.5)$ & $22(22.9)$ & & \\
\hline Vascular invasion & & & & 0.251 & & & 0.088 & \\
\hline No & $129(81.1)$ & $19(73.1)$ & $110(82.7)$ & & $47(74.6)$ & $82(85.4)$ & & \\
\hline Yes & $30(18.9)$ & $7(26.9)$ & $23(17.3)$ & & $16(25.4)$ & $14(14.6)$ & & \\
\hline Preoperative therapy & & & & 0.865 & & & 0.819 & \\
\hline No & $148(93.1)$ & $24(92.3)$ & $124(93.2)$ & & $59(93.7)$ & $89(92.7)$ & & \\
\hline Yes & $11(6.9)$ & $2(7.7)$ & $9(6.8)$ & & $4(6.3)$ & $7(7.3)$ & & \\
\hline Tumor type & & & & 0.066 & & & $<0.001^{*}$ & \\
\hline SCLC & $94(59.1)$ & $14(14.9)$ & $80(85.1)$ & & $47(50)$ & $47(50)$ & & \\
\hline LCNEC & $28(17.6)$ & $9(32.1)$ & $19(67.9)$ & & $16(57.1)$ & $12(42.9)$ & & \\
\hline TC & $35(22.0)$ & $3(8.6)$ & $32(91.4)$ & & $0(0.0)$ & $35(100.0)$ & & \\
\hline$A C$ & $2(1.3)$ & $0(0.0)$ & $2(100.0)$ & & $0(0.0)$ & $2(100.0)$ & & \\
\hline Pathological grading & & & & 0.122 & & & $<0.001^{*}$ & \\
\hline High & $122(76.7)$ & $23(88.5)$ & $99(74.4)$ & & $63(100.0)$ & $59(61.5)$ & & \\
\hline Low & $37(23.3)$ & $3(11.5)$ & $34(25.6)$ & & $0(0.0)$ & $37(38.5)$ & & \\
\hline Lymph node metastasis & & & & 0.377 & & & 0.113 & $13(8.2)$ \\
\hline No & $83(52.2)$ & $15(65.2)$ & $68(55.3)$ & & $30(49.2)$ & $53(62.4)$ & & \\
\hline Yes & $63(47.8)$ & $8(34.8)$ & $55(44.7)$ & & $31(50.8)$ & $32(37.6)$ & & \\
\hline Clinical Staging & & & & 0.309 & & & 0.077 & $15(9.4)$ \\
\hline । & $70(48.6)$ & $14(63.6)$ & $56(45.9)$ & & $25(43.1)$ & $45(52.3)$ & & \\
\hline$\|$ & $27(18.8)$ & $3(13.6)$ & $24(19.7)$ & & $8(13.8)$ & $19(22.1)$ & & \\
\hline III & $47(32.6)$ & $5(22.7)$ & $42(34.4)$ & & $25(43.1)$ & $22(25.6)$ & & \\
\hline CD8 density $/ \mathrm{mm}^{2}$ in stroma & & & & $0.002^{*}$ & & & $0.005^{*}$ & \\
\hline$\leq 264.6 / \mathrm{mm}^{2}$ & $80(50.3)$ & $6(23.1)$ & $74(55.6)$ & & $23(36.5)$ & $57(59.4)$ & & \\
\hline$>264.6 / \mathrm{mm}^{2}$ & $79(49.7)$ & $20(76.9)$ & $59(44.4)$ & & $40(63.5)$ & $39(40.6)$ & & \\
\hline
\end{tabular}


necrosis $(p<0.001)$, high pathologic grade $(p<0.001)$, and histologic type (particularly for LCNEC) $(p<0.001)$.

\section{Correlations among CD8+ T cell infiltration and clinicopathologic parameters}

CD8+ TILs grading was subdivided into two groups based on the median CD8+ T cell density within stroma $\left(264.6 / \mathrm{mm}^{2}\right)$ in PNETs (Table 2). Higher CD8+ T cell density $\left(>264.6 / \mathrm{mm}^{2}\right)$ was associated with the absence of vascular invasion $(p=0.004)$, histologic type (particularly for AC) $(p=0.005)$, negative lymph node metastasis $(p=0.005)$, and lower clinical staging $(p=0.007)$. No correlation was observed between CD8+ TILs and age, gender, necrosis or neoadjuvant therapy.
PD-L1 expression was positively correlated with CD8+ TIL expression within stroma. Figure 1 presents the patterns of PD-L1 expression and CD8+ T cell infiltration in high-grade and low-grade malignancies.

\section{Association of PD-L1 expression and CD8+ TILs with OS and PFS}

Univariate survival analysis showed a trend toward an association between positive expression of PD-L1 in patients with PNETs and decreased OS $(p=0.158)$ and PFS $(p=0.315)$. However, this trend did not reach the level of statistical significance. Similarly, expression of PD-L1 on tumor cells showed a related trend toward poorer OS $(p=0.459)$ and PFS $(p=0.708)$ (Fig. 2).

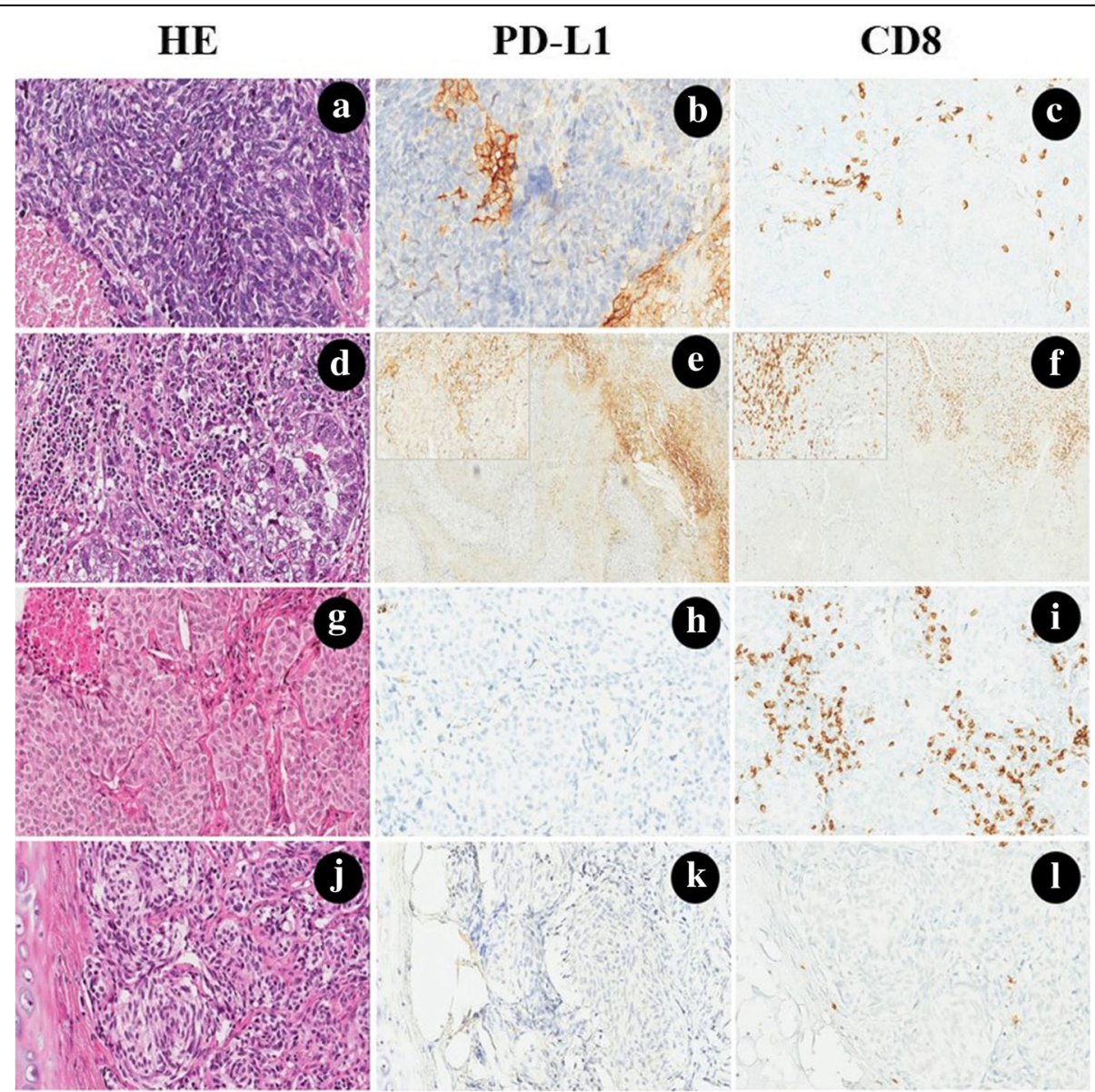

Fig. 1 Hemotoxylin and eosin (H\&E), PD-L1 and CD8 stains, each performed on histologic sections of small cell lung cancer (a-c), large cell neuroendocrine carcinoma (d-f), atypical carcinoid ( $\mathbf{g}-\mathbf{i})$ and typical carcinoid (j-I). a Small cell lung cancer was showing a scant cytoplasm, fine nuclear chromatin, absent or inconspicuous nucleoli, extensive necrosis. b PD-L1 was moderately expressed on the membrane of stromal immune cells in the desmoplastic stroma between clusters of tumor cells. c CD8+ TILs were observed in the stroma, while the intratumoral pattern of CD8 expression was not common. $\mathbf{d}$ Large cell neuroendocrine carcinoma with prominent nucleoli and abundant eosinophilic cytoplasm, necrosis was not shown. e, f PD-L1 was positively expressed on the membrane and cytoplasm of the immune cells, and a large number of CD8+ TILs could also be observed at the borderline (the 200x magnification for PD-L1 and CD8 was shown in the upper left, respectively). g Atypical carcinoid with vascularized stroma, focal necrosis and 6 mitosis/2 mm². $^{2}$, i PD-L1 was negative expression either in tumor cells or stromal cells, while CD8+ TILs were exhibited in the interface of tumor and stroma. $\mathbf{j}$ Typical carcinoid with organoid growth pattern with intervening vascular stroma. $\mathbf{k}$ I No PD-L1 can be detected, and only several CD8+ TILs could be found in the stroma. (The original magnification of e-f was 100x, magnification for remaining cases were 200x) 


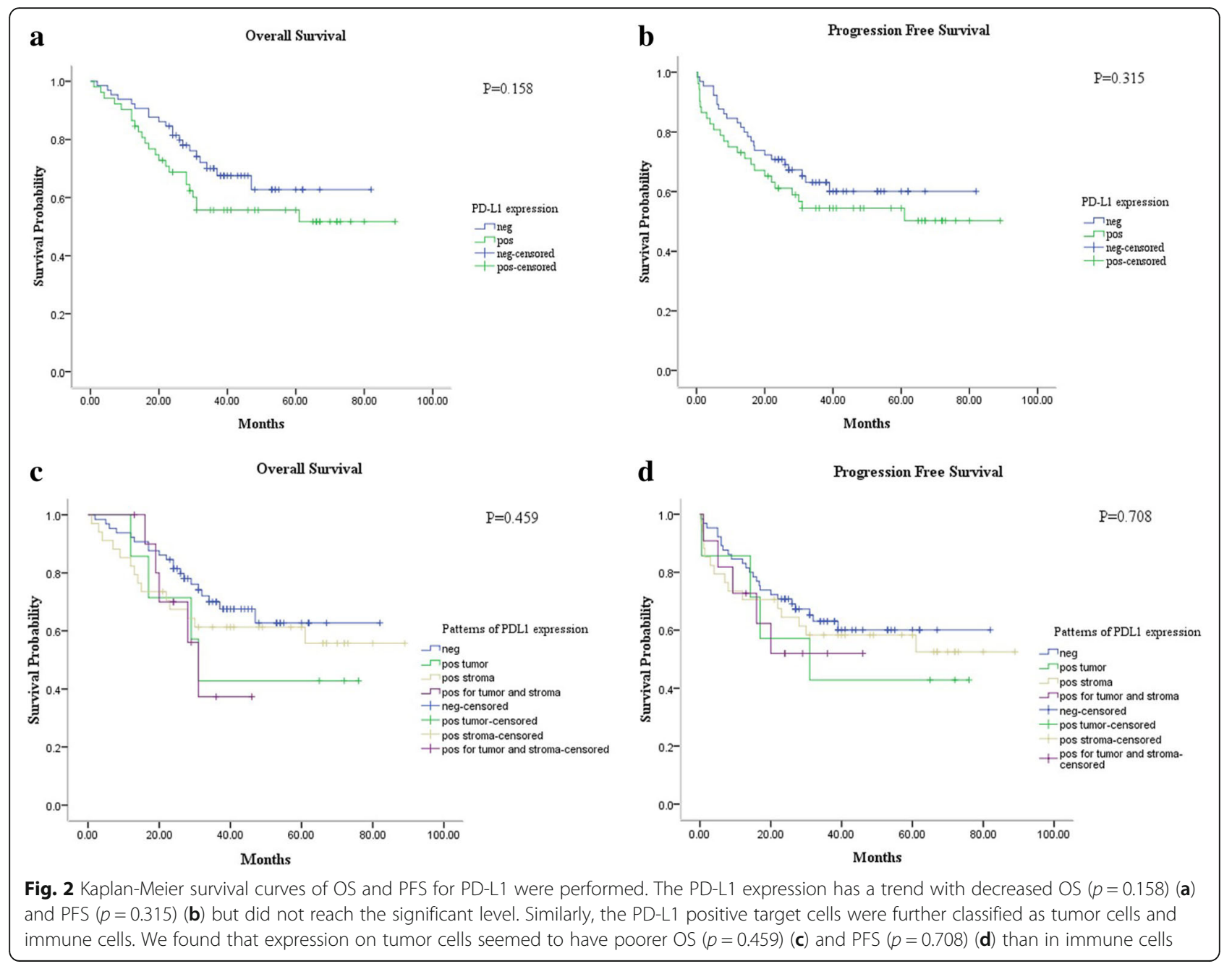

We also evaluated the relationship of CD8+ TIL density in stromal and intratumoral areas with OS and PFS. Immune stromal CD8+ $\mathrm{T}$ cell density was classified as low $\left(\leq 264.6 / \mathrm{mm}^{2}\right)$ or high $\left(>264.6 / \mathrm{mm}^{2}\right)$. Intratumoral CD8+ $\mathrm{T}$ cell density was also subdivided as low $\left(\leq 24.5 / \mathrm{mm}^{2}\right)$ or high $\left(>24.5 / \mathrm{mm}^{2}\right)$. The presence of high CD8+ TIL density in stroma proved to be a better prognostic factor for improved OS $(p=0.000)$ and PFS $(p=0.000)$. No correlation between intratumoral CD8 $+\mathrm{T}$ cell density and OS $(p=0.417)$ or PFS ( $p=0.387)$ was observed (Fig. 3$)$.

For multivariate analysis, the Cox proportional hazards model was performed and included age, gender, necrosis, vascular invasion, lymph node metastasis, clinical staging, PD-L1 expression and CD8+ TILs in the stroma. The results revealed that expression of PD-L1 was not an independent prognostic factor for OS (Hazard ratio $[\mathrm{HR}]=$ 0.707 ; 95\% confidence interval [CI], 0.367-1.364; $p=$ 0.301 ) or PFS (Hazard ratio $[H R]=0.921 ; 95 \%$ confidence interval $[\mathrm{CI}], 0.420-2.021 ; p=0.838)$. In contrast, the presence of high CD8+ TIL density in stroma was an independent prognostic factor for improved OS (Hazard ratio
$[\mathrm{HR}]=2.770$; 95\% confidence interval $[\mathrm{CI}], 1.294-5.930$; $p=0.009$ ) and PFS (Hazard ratio $[\mathrm{HR}]=3.011 ; 95 \%$ confidence interval $[\mathrm{CI}], 1.492-6.079 ; p=0.002)$.

\section{Discussion}

In this study, we investigated the associations between PD-L1 and other clinicopathologic characteristics. Our examination of PNETs showed that expression of PD-L1 was significantly associated with high pathologic grade, advanced histologic type and presence of tumor necrosis. These results reflect the increase in total mutation frequency associated with the malignancy of tumor type. High-grade SCLC and LCNEC have a higher somatic mutation rate ( $>7$ per million base pairs) than the lung carcinoids (0.4 per million base pairs) [15]. Thus, the high-grade carcinoma might secret stronger neoantigens to generate higher immunogenicity to recruit more cytotoxic $\mathrm{T}$ lymphocytes to kill non-self-components. Then, PD-L1, which is expressed by tumor cells, is increased to resist the immune protection function of CD8+ TILs. 


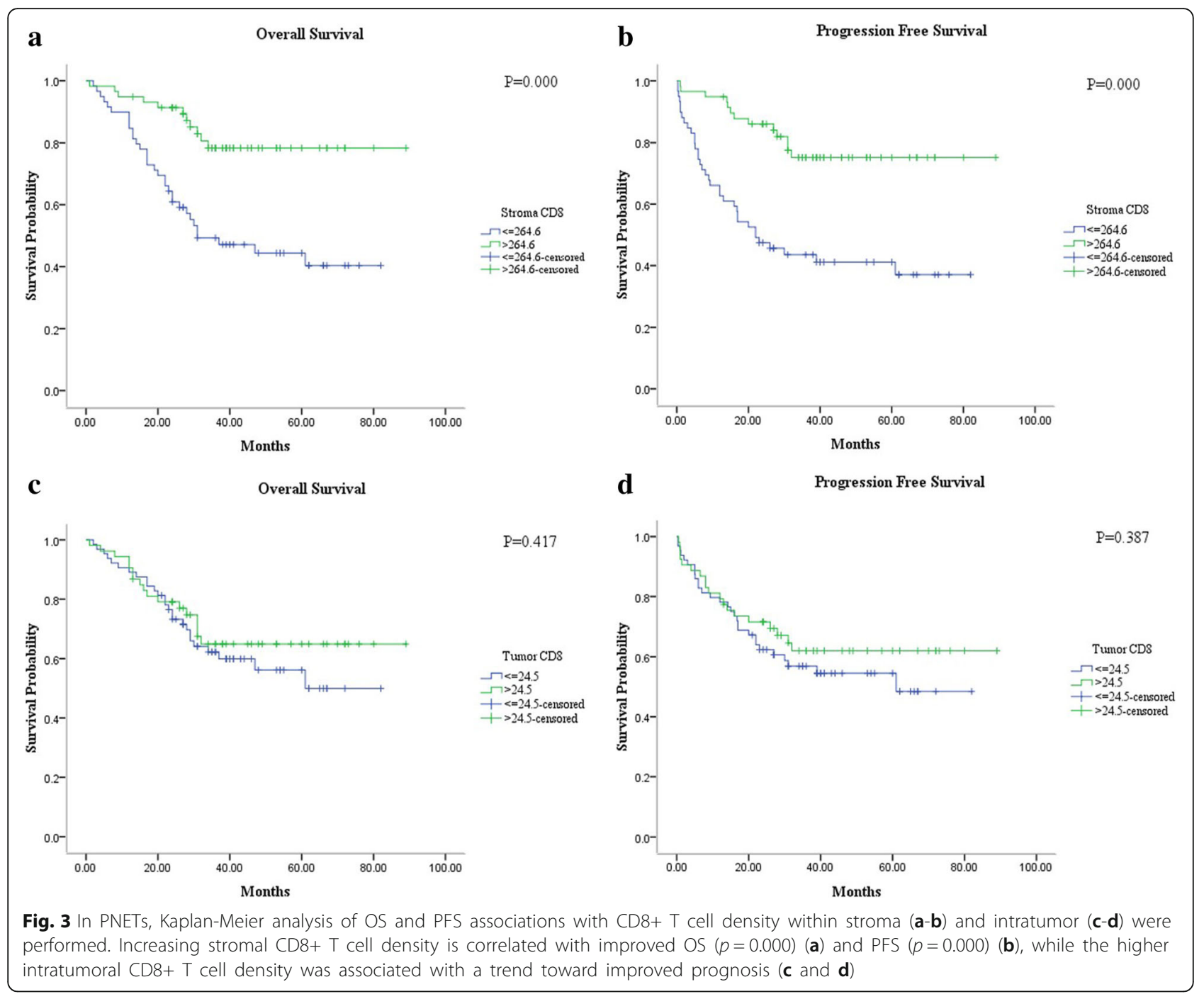

Inflammatory cytokines, particularly interferon gamma (INF-r), can up-regulate PD-L1 expression in various cell types including tumors. In both melanoma and squamous cell carcinoma of head and neck (HNSCC), INF-r has been highlighted as a major cytokine driving PD-L1 expression $[16,17]$. This indicates that PD-L1 is upregulated in tumor cells in response to secretion of INF by CD8+ T cells, as an adaptive immune-resistance mechanism that suppresses local effector T-cell function [18-20]. The results detailed above indicate that positive expression of PD-L1, especially in tumor cells, is associated with a trend toward decreased OS and PFS of PNETs. Such a trend is consistent with results previously published [21]. Moreover, we found that PD-L1 expression was predominantly present at the tumor-stroma margin, in the presence of accumulated stromal CD8+ T cells. This indicates that the PD-L1 expression manifests as a result of forces favoring tumor progression, while stromal CD8+ $\mathrm{T}$ cell infiltration manifests as a result of the body's efforts at immune protection [17].
We also found that the higher CD8+ T cell density, the higher it was significantly associated with the absence of vascular invasion, negative lymph node metastasis and lower clinical staging. These findings may partially explain why stromal presence of CD8+ $\mathrm{T}$ cell infiltration was an independent factor for favorable OS and PFS in neuroendocrine carcinomas of the lung.

Notably, we detected PD-L1 expression in 45.3\% (72/ 159) of neuroendocrine carcinoma of the lung. Our result was inconsistent with the study conducted by Schultheis et al. [13]. In that study, they found that tumor-infiltrating macrophages (TIMs) and tumor-infiltrating lymphocytes (TILs) rather than tumor cells showed PD-L1 protein expression. Additionally, the positive rate of PD-L1 in our study was lower than the result previously reported [21]. The inconsistent results can be attributed to the different antibodies and different criteria of scoring used in different studies. 
Nonetheless, our study reports several important findings that may have implications for targeting PD-L1 immunotherapy in PNETs. First, we proved that CD8+ T cell infiltration was positively correlated with PD-L1 expression, which indicates an adaptive immune resistance-type mechanism that can also be observed in PNETS. Second, while the PD-L1 expression was observed in $16.4 \%$ of the tumor cells, 39.6\% cases of PNETs showed PD-L1 expression in the immune cells at the invasive stroma-tumor margin. Though it has increasingly been recognized that PD-L1 expression on immune cells at the invasive margin represents evidence of an immune resistance mechanism, in our study, the PD-L1 expression on tumor cells was of great importance to predict the prognosis $[18,22]$. Third, we showed a trend toward the correlation between expression of PD-L1 and decreased OS and PFS. This may provide a theoretical basis for anti-PD-L1 immunotherapy in PNETs. Moreover, increased CD8+ TILs density in stroma was an independent prognostic factor for improved OS and PFS. When sufficient $\mathrm{T}$ cells present in the tumor induce an adaptive expression of PD-L1, the PD-L1+/CD8+ patients may be most likely to respond to anti-PD-1/PD-L1 therapy. Therefore, there is a need for quantitative assessment of TIL and PD-L1 presence in resected samples to produce the desired predictive information [23].

Use of traditional treatments such as chemotherapy and radiotherapy may lead to the emergence of tumor-associated antigens, which was released from the apoptotic tumor cells [24]. If the initial traditional therapy can effectively present the tumor cells as foreign tumor antigens, it is obvious that subsequent immunotherapy is possible to be a favorable endeavor [25]. Recent studies have reported that the presence of TILs may predict a positive response to neoadjuvant chemotherapy [26]. We, therefore, sought to select patients who were more available for the immunotherapy, to maximize the benefit derived from the chemotherapy/ radiotherapy-immunotherapy combined strategies.

Though we believe our study illustrates the value of PD-L1 as a potential prognostic marker, there were some limitations. First, this study involved a relatively small number of patients. This small sample size may have resulted in selection bias. Second, mature survival information was limited as the follow-up duration in our study was not long enough to fully evaluate 5 -year survival rates.

\section{Conclusion}

We found that PD-L1 was expressed in half of the PNETs and associated with necrosis, high pathologic grade and advanced histologic type. PD-L1 expression was observed primarily in immune stromal cells but showed no associations with OS or PFS. In contrast, higher levels of CD8+ TILs observed in stroma were associated with the absence of vascular invasion, negative lymph node metastasis, lower clinical staging and was demonstrated to be an independent factor for improved OS and PFS. Our results may highlight a promising method for the selection of patients with PNETs who are most likely to benefit from immunotherapy in the future.

\begin{abstract}
Abbreviations
AC: Atypical carcinoid; APCs: Antigen-presenting cells; CTLs: Cytotoxic lymphocytes; FFPE: Formalin-fixed paraffin-embedded; HNSCC: Squamous cell carcinoma of head and neck; IHC: Immunohistochemistry; INFг: Inteferon gamma; LCNEC: Large cell neuroendocrine carcinoma; mAbs: Monoclonal antibodies; OS: Overall survival; PD-L1: Programmed death-ligand 1; PFS: Progression free survival; PNETs: Pulmonary neuroendocrine tumors; SCLC: Small cell lung carcinoma; TC: Typical carcinoid; TILs: Tumor-infiltrating lymphocytes; TIMs: Tumor-infiltrating macrophages
\end{abstract}

\section{Funding}

This study was supported by the Beijing Municipal Science and Technology Commission NOVA program (NO.2010 B033), the Beijing Municipal Science and Technology Commission Capital Characteristic Clinical Application Research (No.Z141107002514077), the National Nature Science Foundation of China (No.61501039), and grants from the funding of the Beijing Cancer Hospital (approval \#:13-11).

\section{Availability of data and materials}

The raw data are available upon request on the following e-mail address: hyuewang@163.com.

\section{Authors' contributions}

$\mathrm{DML}$ and $Z W L$ conceived and designed the experiments. $H Y W, Z W L, B D, X Y$, $X Z H$ and $L J$ performed the experiments. HYW, ZWL, BD, WS and RPL analyzed the data. BD and LXZ contributed the materials/analysis tools for the study. HYW and ZWL wrote the paper. All authors have read and approved the final manuscript.

\section{Ethics approval and consent to participate}

This study was approved by the ethics committee of Peking University Cancer Hospital \& Institute (Permission number 2013KT35). Additional patient consent for this retrospective study was not required.

\section{Competing interests}

The authors declare that they have no competing interests.

\section{Publisher's Note}

Springer Nature remains neutral with regard to jurisdictional claims in published maps and institutional affiliations.

\section{Author details}

${ }^{1}$ Key Laboratory of Carcinogenesis and Translational Research (Ministry of Education), Department of Pathology, Peking University Cancer Hospital \& Institute, No. 52 Fucheng Road, Haidian District, Beijing 100142, People's Republic of China. ${ }^{2}$ Key Laboratory of Carcinogenesis and Translational Research (Ministry of Education), Department of Central Laboratory, Peking University Cancer Hospital \& Institute, Beijing 100142, People's Republic of China. ${ }^{3}$ Beijing Institute of Graphic Communication, Beijing 102600, People's Republic of China.

Received: 10 January 2018 Accepted: 13 May 2018

Published online: 22 May 2018

References

1. Travis WD. Advances in neuroendocrine lung tumors. Ann Oncol. 2010; 21(Suppl 7):vii65-71.

2. Rekhtman N. Neuroendocrine tumors of the lung: an update. Arch Pathol Lab Med. 2010;134:1628-38.

3. Bertino EM, Confer PD, Colonna JE, Ross P, Otterson GA. Pulmonary neuroendocrine/carcinoid tumors: a review article. Cancer. 2009;115: 4434-41. 
4. Metro G, Duranti S, Fischer MJ, Cappuzzo F, Crino L. Emerging drugs for small cell lung cancer - an update. Expert Opin Emerg Drugs. 2012;17:31-6.

5. Ohaegbulam KC, Assal A, Lazar-Molnar E, Yao Y, Zang X. Human cancer immunotherapy with antibodies to the PD-1 and PD-L1 pathway. Trends Mol Med. 2015;21:24-33.

6. Herbst RS, Soria JC, Kowanetz M, et al. Predictive correlates of response to the anti-PD-L1 antibody MPDL3280A in cancer patients. Nature. 2014;515:563-7.

7. Khoja L, Kibiro M, Metser U, et al. Patterns of response to anti-PD-1 treatment: an exploratory comparison of four radiological response criteria and associations with overall survival in metastatic melanoma patients. $\mathrm{Br} J$ Cancer. 2016;115:1186-92.

8. Hamid O, Robert C, Daud A, et al. Safety and tumor responses with lambrolizumab (anti-PD-1) in melanoma. N Engl J Med. 2013;369:134-44.

9. Ramos-Esquivel A, van der Laat A, Rojas-Vigott R, Juarez M, CorralesRodriguez L. Anti-PD-1/anti-PD-L1 immunotherapy versus docetaxel for previously treated advanced non-small cell lung cancer: a systematic review and meta-analysis of randomised clinical trials. ESMO Open. 2017;2:e000236.

10. Powles T, Eder JP, Fine GD, et al. MPDL3280A (anti-PD-L1) treatment leads to clinical activity in metastatic bladder cancer. Nature. 2014;515:558-62.

11. Domagala-Kulawik J. The role of the immune system in non-small cell lung carcinoma and potential for therapeutic intervention. Transl Lung Cancer Res. 2015:4:177-90.

12. Aerts JG, Hegmans JP. Tumor-specific cytotoxic T cells are crucial for efficacy of immunomodulatory antibodies in patients with lung cancer. Cancer Res. 2013;73:2381-8.

13. Schultheis AM, Scheel AH, Ozretic L, et al. PD-L1 expression in small cell neuroendocrine carcinomas. Eur J Cancer. 2015;51:421-6.

14. Thompson ED, Zahurak M, Murphy A, et al. Patterns of PD-L1 expression and CD8 T cell infiltration in gastric adenocarcinomas and associated immune stroma. Gut. 2017;66:794-801.

15. Vollbrecht $C$, Werner $R$, Walter RF, et al. Mutational analysis of pulmonary tumours with neuroendocrine features using targeted massive parallel sequencing: a comparison of a neglected tumour group. Br J Cancer. 2015; 113:1704-11.

16. Lyford-Pike S, Peng S, Young GD, et al. Evidence for a role of the PD-1: PDL1 pathway in immune resistance of HPV-associated head and neck squamous cell carcinoma. Cancer Res. 2013:73:1733-41.

17. Taube JM, Anders RA, Young GD, et al. Colocalization of inflammatory response with B7-h1 expression in human melanocytic lesions supports an adaptive resistance mechanism of immune escape. Sci Transl Med. 2012;4: 127 ra137.

18. Tumeh PC, Harview CL, Yearley JH, et al. PD-1 blockade induces responses by inhibiting adaptive immune resistance. Nature. 2014;515:568-71.

19. Taube JM, Young GD, McMiller TL, et al. Differential expression of immune regulatory genes associated with PD-L1 display in melanoma: implications for PD-1 pathway blockade. Clin Cancer Res. 2015;21:3969-76.

20. Pardoll DM. The blockade of immune checkpoints in cancer immunotherapy. Nat Rev Cancer. 2012;12:252-64.

21. Fan Y, Ma K, Wang C, et al. Prognostic value of PD-L1 and PD-1 expression in pulmonary neuroendocrine tumors. Onco Targets Ther. 2016;9:6075-82.

22. Topalian SL, Hodi FS, Brahmer JR, et al. Safety, activity, and immune correlates of anti-PD-1 antibody in cancer. N Engl J Med. 2012;366:2443-54.

23. Teng MW, Ngiow SF, Ribas A, Smyth MJ. Classifying cancers based on T-cell infiltration and PD-L1. Cancer Res. 2015;75:2139-45.

24. Twyman-Saint Victor C, Rech AJ, Maity A, et al. Radiation and dual checkpoint blockade activate non-redundant immune mechanisms in cancer. Nature. 2015:520:373-7.

25. Dushyanthen S, Beavis PA, Savas P, et al. Relevance of tumor-infiltrating lymphocytes in breast cancer. BMC Med. 2015;13:202.

26. Yamaguchi R, Tanaka M, Yano A, et al. Tumor-infiltrating lymphocytes are important pathologic predictors for neoadjuvant chemotherapy in patients with breast cancer. Hum Pathol. 2012;43:1688-94.

\section{Ready to submit your research? Choose BMC and benefit from:}

- fast, convenient online submission

- thorough peer review by experienced researchers in your field

- rapid publication on acceptance

- support for research data, including large and complex data types

- gold Open Access which fosters wider collaboration and increased citations

- maximum visibility for your research: over $100 \mathrm{M}$ website views per year

At BMC, research is always in progress.

Learn more biomedcentral.com/submissions 